\title{
Racial Justice Activist Burnout of Women of Color in the United States: Practical Tools for Counselor Intervention
}

\section{Rudney Danquah ${ }^{1} \cdot$ Cristal Lopez $^{1} \cdot$ Laurel Wade $^{1} \cdot$ Linda G. Castillo $^{1} \mathbb{D}$}

Accepted: 2 August 2021 / Published online: 26 August 2021

(C) The Author(s), under exclusive licence to Springer Science+Business Media, LLC, part of Springer Nature 2021

\begin{abstract}
The pervasive racially hostile climate in society can bring severe mental health ramifications, such as burnout, to racial justice activists. For women of color (WOC), intersecting identities presents additional challenges. Due to the significant psychological impact burnout can have on WOC activists, counselors need the knowledge and tools to address this mental health issue. This article aims to provide counselors with a guide to working with WOC racial justice activists in the United States by outlining challenges faced by this population, health and mental health effects of burnout, and counseling interventions.
\end{abstract}

Keywords Burnout · Racial justice activist · Women of color · Intersectionality · Interventions

The weight of systemic oppression racial justice activists confront is stark as witnesses capture on video, often in real-time, violent instances of race-based injustice that are shown throughout the world (Richardson, 2020). Many activists face the immensity of explicit acts of racism, such as the frequently captured violence against Black and African American individuals by police and anti-immigrant rhetoric in political discourse. People of color (POC) who seek equity also confront a cultural landscape of White fragility that responds to activists with accusations of reverse racism and being a threat to American values (Bucholtz, 2019). The lived experiences of racism combined with the backlash and weight of activist work are physically and emotionally taxing for many POC racial justice activists, often leaving them feeling cynical and ineffective (Maslach \& Gomes, 2006).

Linda G. Castillo

lcastillo@tamu.edu

1 Department of Educational Psychology, Texas A\&M University, College Station,

TX 77843-4225, USA 
For women of color (WOC) activists, intersectionality can also play a role in how experiences of sexism and gender-role expectations are experienced (Gorski, 2019; Mollen \& Ridley, 2021). Rooted in Black feminism and women of color activism discourse (Moradi \& Grzanka, 2017), intersectionality is a term used to describe how an individual's layers of social and cultural identities can affect their experience of oppression and privilege (Crenshaw, 1989; Lenes et al., 2020). The social inequities women of color activists experience daily are compounded by power dynamics that can occur within activist organizations and contribute to mental exhaustion and burnout (Gorski, 2019; Moradi \& Grzanka, 2017).

Campaigning for social change in a racially hostile climate can affect racial justice activists' wellbeing and impact the sustainability of a movement (Maslach \& Gomes, 2006; Schaufeli \& Buunk, 2002). For many WOC activists, well-being and self-care are often neglected and can make them more susceptible to burnout (Chen $\&$ Gorski, 2015). However, scholars suggest that developing educational and practical tools to reduce stress can prevent and decrease burnout symptoms (Awa et al., 2010; Posluns \& Gall, 2019). The purpose of this article is to provide counselors with the tools needed to assist WOC racial justice activists experiencing burnout by providing an overview of (a) two common psychosocial stressors; (b) physical and mental health effects, and (c) recommended empirically established counseling tools.

\section{What is Activist Burnout?}

Burnout is a persistent state of physical and mental exhaustion that affects an individual's well-being and functioning (Posluns \& Gall, 2019). For activists, burnout also includes disillusionment and loss of passion for a cause. (Chen \& Gorski, 2015). Given that burnout can affect racial justice activists' well-being and the momentum driving their work, counselors need to understand the various components of burnout.

Racial justice activist burnout is comprised of three components: internal, external, and in-movement (Gorski, 2019). The internal component is a self-induced pressure for social change that comes from a deep sense of commitment to a cause as well as knowledge of the structural conditions that inhibit change (Gorski, 2019). Activists sometimes experience feelings of despair or guilt because of the magnitude of systemic change needed and the resistance of society to amend oppressive systems in response (Chen \& Gorski, 2015).

The external component consists of actual or potential threats of violence (Gorski, 2019). External threats can range from harassment and character assassination (Jones, 2007) to physical violence (Jacobs \& Taylor, 2011). For instance, during the Dakota Access Pipeline protests, news reports noted that law enforcement fired at roughly 400 protestors with rubber bullets, tear gas, and water (Park \& Cuevas, 2016).

Activists of color are more likely to be targets of violence, particularly at raciallycharged protests. One study found that during a protest in the United States, police responded with greater levels of physical violence toward Black and African 
American activists than White activists (Davenport et al., 2011). For example, several U.S.-based activists of color faced tear gas and arrest when protesting the acquittal of a former police officer in the shooting of Anthony Lamar Smith in Michigan (St. Louis Public Radio, 2017).

The third component of racial justice activist burnout is in-movement (Gorski, 2019). This occurs when interpersonal conflicts within a movement may be more responsible for activist burnout than internal or external components such as experiencing racism from other members within the movement, ego and leadership clashes, sexism, and sexual harassment (Gorski, 2019; Maslach \& Gomes, 2006). For instance, in a qualitative study of U.S. racial justice activists, several female participants commented that male activists sexually harassed or assaulted them. They could not speak out because of fear that doing so would harm the movement. This led to what participants referred to as "a sort of conspiracy of silence about burnout" where negative concerns about the movement are squelched (Chen \& Gorski, 2019, p. 379).

\section{Psychosocial Stressors}

In addition to the societal retaliation and financial vulnerability many activist experience (Gorski et al., 2019), U.S. racial justice activists of color face psychosocial stressors such as pressure to embrace a culture of selflessness and racial battle fatigue, which has been associated with burnout and other negative mental health outcomes (Giordano et al., 2020; Gorski, 2019). Racial justice activism often requires a significant emotional investment. An indicator of an activist's commitment to a movement is frequently measured by the amount of emotional labor invested (Chen \& Gorski, 2015). Although maintaining high levels of emotional labor contributes to negative mental health outcomes (Giordano et al., 2020; Gorski, 2019; McKim \& Smith-Adcock, 2014), discussions about burnout may be suppressed because of the expectation that activists engage in selfless work (Chen \& Gorski, 2015; Pigni, 2016).

Similar to racial justice activists, counselors invest high amounts of emotional labor in their work with clients. Counselor empathy and a deep understanding of a client's worldview are central to their clinical work (McKim \& Smith-Adcock, 2014). This emotional investment may place counselors at risk of burnout. This is particularly the case when working with clients dealing with trauma, such as racebased trauma (Giordano et al., 2020; McKim \& Smith-Adcock, 2014). For instance, a study of U.S. counselors and secondary trauma (a known correlate of burnout) examined the effects of clients' reports of racial discrimination on counselors' wellbeing (Giordano et al., 2020). The study found that hearing client reports of racism significantly predicted counselor secondary traumatic stress. Although counselors are well versed in self-care techniques to mitigate stress, self-care is often not a priority because taking the time to do so may be viewed as selfish (Posluns \& Gall, 2019). This mentality can contribute to what has been referred to as a culture of selflessness. 


\section{Culture of Selflessness}

Within an activist culture, there is often an expectation that activists are selfless individuals who sacrifice for the good of an organization in order to prove their commitment to a cause. Scholars refer to this norm as a culture of selflessness (Gorski, 2019). A common method of demonstrating adherence to this expectation is through the number of hours worked, referred to as a "long hours culture" (Bradley et al., 2005 , p. 216). The number of hours worked is deemed a reflection of an individual's level of commitment to the organization. For some activists, expressing emotional or physical exhaustion is perceived as a badge of honor (Gorski et al., 2019; Pigni, 2016). Organizational leadership may also propagate this culture of selflessness within their organization by providing rewards or promotions for working longer hours (González, 2015). For many WOC activists, the expectation to demonstrate selflessness as a badge of honor can be problematic.

Selflessness is often associated with the gender role expectation that women must be nurturers (Lips, 2020). For WOC, this expectation also overlaps with a collectivistic culture's norm that members give back to the community (Akkus et al., 2017). Research suggests these gender and cultural expectations are associated with distress (Abrams et al., 2019). For example, adhering to the female gender role of caretaking, nurturing, and selflessness has been linked to depression and anxiety (Nuñez et al., 2016). Furthermore, WOC in the United States experience greater distress from adhering to gender roles than their Westernized White peers (Lips, 2020). Given the distress gender and cultural expectations can have, WOC racial justice activists may find that the cumulative impact of multiple minoritized identities (i.e., $\mathrm{POC}$ and female) can exacerbate burnout.

\section{Racial Battle Fatigue}

Another psychosocial stressor experienced by racial justice activists is racial battle fatigue. Racial battle fatigue is a response to long-term accumulated racial stressors whereby an individual's emotional resources are taxed due to balancing internal conflicts (e.g., coping with racism) and external experiences (e.g., experiencing racism). The accumulation of these internal and external stressors often leads to physical and emotional symptoms associated with burnout (Gorski, 2019).

Research on racial battle fatigue in the United States points to activists' frustration and anger toward systemic racial injustices (Blaisdell, 2016). U.S. activists of color battle racist experiences not only from within their community but also from other activist circles and organizations (Gorski, 2019). Growing feelings of anger may stem from feeling obligated to engage in racial justice activism because they are a person of color (Linder \& Rodriguez, 2012). Frustration often occurs when activists feel pressure to produce a large-scale impact in a society that does not put the same effort into creating change on racial justice issues (Rodgers, 2010).

The hostile environment that activists work in further exacerbates their anger and frustration. Activists sometimes find themselves in organizations and movements 
where members compete with one another rather than work in cooperation towards a common goal. White racial justice activists and White allies within anti-racism movements sometimes replicate the racism they are fighting against. The anger and frustration felt by the activists of color are exacerbated due to various components, such as having their work undermined and others taking credit for their work (Gorski, 2019; Gorksi \& Erakat, 2019). Activists of color dealing with racial battle fatigue may have a difficult time being present in their activist work because the injustices they are working to remove are manifested within their movements and organizations.

Over time, racial battle fatigue creates a constant undercurrent of anger and frustration with an organization that becomes normalized (Rodgers, 2010). Having to endure strong, negative emotions in organizations that may not promote self-care or wellness may lead racial justice activists to search for alternative ways to regulate their emotions. Because of this, activists may turn to suppressing or concealing their emotions, particularly when a culture of selflessness is considered (Chen \& Gorski, 2015).

Because intersecting identities have various levels of systemic privilege that influence a person's experiences and worldview (Lenes et al., 2020), racial battle fatigue may be experienced differently for WOC in the United States. For instance, WOC have different experiences of discrimination due to skin tone and hair texture, which can influence their racial identity (Laidley et al., 2019; Maxwell et al., 2015). Although social justice scholars have noted that the complexity of intersecting identities are shaped by power dynamics of privilege and oppression (Moradi \& Grzanka, 2017), activist groups continue to focus on one aspect of identity. As such, WOC may be forced to choose between marginalized identities. For example, a qualitative study of U.S. WOC activists found that participants reported feeling pressured to select certain identities (e.g., gender vs. race) within particular contexts (Linder \& Rodriquez, 2012). The act of balancing their identities and being forced to choose between them is associated with activists feeling marginalized and isolated.

Gender differences in how emotions are regulated can also contribute to how racial battle fatigue is experienced by WOC racial justice activists. For instance, research suggests that women utilize rumination (i.e., persistent and chronic focus on negative experiences) to regulate emotion (McRae et al., 2008; Nolen-Hoeksema, 2012). For WOC racial justice activists who are already experiencing racial battle fatigue, ruminating over systemic racial injustices on top of difficulties in the activist's organization can add to their stress and frustration.

\section{Effects of Burnout}

\section{Physical Health}

Burnout can affect an individual's physical health (Chen \& Gorski, 2015; Rodgers, 2010; Salvagioni et al., 2017). Studies on racial justice activists note a decline in their physical health in part because of a chronic absence of self-care (Gorski \& Chen, 2015). For instance, some activists have reported chronic sleep issues and 
insomnia (Chen \& Gorski, 2015). Chen and Gorski noted that rather than practicing self-care, activists increased their usage of sleeping pills to the extent that some experienced signs of addiction.

A systematic review found that cardiovascular diseases are the most commonly experienced physical outcomes due to burnout (Salvagioni et al., 2017). Burnout was also associated with obesity, type 2 diabetes, hypertension, and high LDL cholesterol. There was also a strong association between burnout, severity of cardiovascular diseases, and hospitalizations (Salvagioni et al., 2017). Scholars speculate that the underlying link between burnout and cardiovascular disease is chronic stress, which triggers the autonomic nervous system and hypothalamic-pituitary-adrenal axis (Simon-Kutscher et al., 2020).

For WOC racial justice activists, racial stress is another factor associated with physical health problems, such as hypertension (Michaels et al., 2019; Moody et al., 2018). For instance, in a study that explored the relationship between racial stress and the physical health of Black and African American women, researchers found that daily experience of racial discrimination was associated with a higher prevalence of hypertension (Michaels et al., 2019).

Sexual harassment is another area WOC activists experience that influences their physical health (Gorski, 2019). One study found that race and sexual orientation were predictors of sexual victimization and posttraumatic stress disorder (PTSD; Sigurvinsdottir \& Ullman, 2016). Similarly, a study of midlife women explored the impact on physical health and found that experiencing sexual harassment was associated with higher blood pressure and poor sleep (Thurston et al., 2018).

\section{Mental Health}

There are numerous studies on the relationship between burnout and mental health issues, such as depression and compassion fatigue (Figley \& Ludick, 2017; Koutsimani et al., 2019). Most studies note a significant association between burnout and depression (Koutsimani et al., 2019), specifically when emotional exhaustion, a component of burnout, is examined (Ahola \& Hakanen, 2007; Bianchi et al., 2015). For instance, in a systematic review of burnout studies, Bianchi et al. noted that emotional exhaustion had a moderate to high correlation with depressive symptoms.

As activists spend high amounts of emotional labor in their work, examining the association between emotional exhaustion and depression is noteworthy. However, Gorski and colleagues are one of few scholars who have examined this relationship, specifically among racial justice activists. In their 2015 study of racial justice activists, Gorski and Chen found that $71 \%$ experienced feeling depressed and isolated. This finding was notable among participant activists of color. Hopelessness, another symptom of depression, was also reported among participants.

Gorski's (2019) qualitative study of student and faculty activists of color at a predominantly White university in the United States further explains occurrences that can reduce the hope for change. The study found that their participation in activism made them susceptible to backlash from both within and outside of their movements. This experience limited their hope for structural change and decreased their 
motivation to persist. For example, some activists experienced retribution for their emotional reactions to oppressive incidents, such as accusations of aggression by university officials and White allies. WOC activists reported experiencing sexism, such as beliefs that male activists were more competent, from male members of the movements as well as inconsistent support from White allies. The participants cited these oppressive experiences contributed to feelings of hopelessness and cynicism (Gorski, 2015, 2019).

Behavioral indicators of depression, such as getting out of bed and interacting with their children, were also noted by racial justice activists (Chen \& Gorski, 2015). This is a common for those experiencing family-work and/or work-family conflict. Often, the strain caused by work or family spills over into other life domains and can negatively affect an individual's mental health (Zhou et al., 2018).

Compassion fatigue is another negative mental health outcome of activist burnout (Figley \& Ludick, 2017). Compassion fatigue is the diminished ability to attend to and be empathic with the trauma and emotional pain of others (Figley, 1995). Compassion fatigue is considered a form of secondary PTSD whereby symptoms are associated with a traumatic event that is experienced indirectly by listening to and connecting with an individual's emotional pain (Figley \& Ludick, 2017). Because many WOC activists internalize the expectation to sacrifice for the good of the cause (i.e., culture of selflessness), compassion fatigue often goes untreated (Rodgers, 2010). Many activists in the United States report regulating their emotions by pushing their emotional health aside by working harder or numbing one's self to protect themselves psychologically (Rodgers, 2010).

Although the effects of compassion fatigue on WOC racial justice activists have not been studied, work done with U.S. WOC who provide counseling in domestic violence shelters provides some insight as to the impact of compassion fatigue, or secondary trauma, on mental health. In a study of African American and Latina mental health providers (Beckerman \& Flaherty, 2019), the study found that secondary traumatic stress was significantly more prevalent among the participants than in the general U.S. population. Notably, study participation required participants to have no known post-traumatic stress symptoms before beginning their clinical work. The most prevalent secondary stress symptom among the participants $(41.6 \%)$ was avoidance, such as wanting to avoid client work or reminders of their clinical experiences. Some participants $(31.5 \%)$ experienced symptoms of having unwanted thoughts about the distressing stories they were exposed to in their client work. Other participants experienced symptoms related to increased anxiety and vigilance related to their clinical work (Beckerman \& Flaherty, 2019).

\section{Barriers to Seeking Counseling}

Racial justice activist work can place a toll on a WOC's physical and mental health. To reduce burnout and maintain activist wellbeing, personal sustainability is needed (Cox, 2011). Personal sustainability involves establishing and maintaining a balance in various aspects of one's life (Cox, 2009). Counselors can assist WOC racial social justice activists to gain the skills needed to maintain personal sustainability. 
However, disparities in access to mental health treatment continue to exist for people of color in the United States, often due to a lack of health insurance (Cohen et al., 2020). Alternative mental health care, such as curanderos/folk healers (Cabassa et al., 2006) or the spiritual community and churches (Allen et al., 2010), are potential low-cost resources U.S. counselors should be aware of and are encouraged to collaborate with such resources to meet the needs of WOC activist who may not be able to afford traditional counseling.

Even when counseling costs are not an issue, some U.S. WOC may not be comfortable with a counselor who differs from their ethnic or racial group. Research suggests client-counselor racial match positively influences a client's willingness to attend counseling and wellbeing (Kim \& Kang, 2018). However, when this is not feasible, cultural competence training with a focus on self-reflection on race and privilege can be beneficial, especially since racial justice activist work centers on addressing systemic racism and White privilege.

Based on the findings of their cross-racial counseling dyad study, Chang and Berk (2009) provided several recommendations to counselors. First, client conceptualization should recognize and attend to all intersecting cultural identities. Second, they encourage counselor awareness of selecting interventions based on making assumptions of the client's cultural group and instead strategically select based on client needs. Next, counselors should actively demonstrate comfort and willingness to selfdisclose White privilege and systematic oppression at play in the session. Finally, counselors should show a willingness to hear the client and not dismiss experiences of marginalization and oppression.

Another barrier that may prevent WOC to seek counseling is the perceived need for help (Chang \& Biegel, 2018). For many U.S. WOC activists, the cultural of selflessness norm combined with cultural gender-role expectations (e.g., strong Black woman or Marianismo ideologies) can be an impediment to recognizing burnout's impact on their mental health and the need to seek counseling (Akkus et al., 2017; Gorski et al., 2019; Pigni, 2016). For instance, the strong Black woman ideal is based on the gender-role expectation that Black women must be a source of emotional and physical strength for their family, church, and community and suppress any sign of weakness or vulnerability (Hall et al., 2021; Stanton et al., 2017). Endorsement of the strong Black woman ideology has been positively associated with emotional avoidance and depression (Harrington et al., 2010; Stanton et al., 2017) and negatively associated with mental health services utilization (Hall et al., 2021). In addressing this, counselors can re-frame this in a manner where seeking self-care is needed to continue their activist work. A WOC activist's commitment to serving the community is used as an incentive to practice self-care and seek mental health support.

\section{Recommendations for Counselors}

Because of the activist cultural norms of sacrificing self for a cause and the lack of discussion on activist wellbeing (Chen \& Gorski, 2015), counselors should address burnout prevention as well as teach counseling techniques to reduce 
burnout symptoms. Burnout intervention studies suggest that person-directed interventions such as psychoeducation, mindfulness, and relaxation techniques are effective in reducing emotional exhaustion and depressive symptoms (Dreison et al. 2018; Mughairbi et al., 2020; Shah et al., 2014; Sharma \& Rush, 2014).

For individuals and communities that may have difficulty accessing affordable mental health services or cannot afford weekly sessions, community-based psychoeducational workshops could reach a larger group of individuals. A psychoeducational workshop can be used as a primary tool to prevent burnout as well as a secondary tool for those who are don't know how to address and manage burnout symptoms. The foundation of the workshop is to provide information about burnout and activities to address burnout symptoms. This would allow activists to recognize burnout's early stages.

With the use of empirical studies, counselors can discuss how burnout manifests in the workplace and give clear examples within the racial justice activist environment. For instance, one component of the workshop could cover issues such as a culture of selflessness and racial battle fatigue. Another component could provide information on the physical and mental health outcomes that are most prevalent for WOC. An example of an activity to address burnout related to a culture of selflessness would be for activists to develop a self-care plan that focuses on taking time to attend to their wellbeing in a way that does not involve their activism and allows them to recharge.

Mindfulness and relaxation interventions are effective counseling tools used to address burnout symptoms (Shah et al., 2014). A difficult component when engaging in racial justice activism is dealing with difficult emotions. There is a misconception among activists that negative emotions, such as anger and frustration, can be used as fuel to energize the activist and make progress in activist movements (Barker et al., 2008). This can be especially problematic for WOC racial justice activists who may suppress their emotions. Mindfulness is a nonjudgmental, intentional manner of guiding the activist client to focus on their state of being. Research suggests that activist clients who engage in mindfulness are better equipped to identify and address their negative emotions (e.g., cynicism and anger; Barker et al., 2008).

Dialectical behavior therapy (DBT) is an empirically established intervention that focuses on client management of difficult emotions through mindfulness (Linehan, 2015). Pulling from DBT, the counselor can review the concept of mindfulness and teach the mindfulness technique known as the wise mind. The wise mind is the synthesis between decisions based on emotions and rationality whereby an individual is guided to search deep within their intuition and wisdom to find a solution (Neacsiu et al., 2012). For WOC activities, the wise mind exercise could be modified to build on cultural strengths. For instance, when reflecting on a problem connected to a negative emotion, the counselor can guide the client to call upon their ancestors' wisdom and listen to their solutions.

Another beneficial mindfulness intervention is the body scan. As WOC are more likely to experience psychosomatic symptoms of stress (Williams, 2018), the body scan allows the individual to attune to the areas in their body that are most affected. Starting at their feet and moving up their body, the client is asked to focus on each part of their 
body and body sensations. The client is encouraged to note places they feel pain or tightness in order to be aware of the areas they hold stress.

In addition to mindfulness in counseling sessions, relaxation techniques can be taught to address the body's stress response by decreasing blood pressure and heart rate (Shah et al., 2014). Activities range from deep breathing to progressive muscle relaxation. For instance, a counselor can instruct clients on the difference between shallow breathing and deep breathing. They can also help the client identify when shallow and rapid breathing is most likely to occur. In addition, the counselor can work with a client in establishing a plan on how the client can practice deep breathing during activist work (e.g., work in deep breathing breaks).

In addition to alleviating symptoms, burnout prevention includes counselors being change agents on a systemic level. Several professional counseling and psychological organizations have called for professionals in the field to advocate for systemic change of various social justice issues (e.g., American Psychological Association, 2017; Toporek \& Daniels, 2018). The American Counseling Association provides a framework for counselors to advocate with and for clients facing systemic barriers (Toporek \& Daniels, 2018). Advocacy interventions range from client empowerment to social/ political advocacy where a counselor acts as a change agent in the system.

One recommended social/political advocacy strategy is for counselors to understand how intersectionality of one's cultural identities influences the way they work with clients and the community (Ridley et al., 2021; Toporek \& Daniels, 2018). For instance, when conceptualizing clients from an intersectionality framework, counselors consider the impact of oppression, as well as areas of internal and external power and privilege that sustain the oppression. Furthermore, counselors should take into account that intersectional analysis is mutually constructed and shaped by client-counselor power dynamics (Moradi \& Grzanka, 2017). Counselors determine the direction of a therapy session as well as dictate what is considered normal or pathological behaviors (e.g., diagnosis). Counselors should be aware that many counseling interventions and theories are grounded in a Western ideology (Sahu et al., 2021). Thus, counselors must approach client case conceptualization with an awareness of the cultural values and beliefs that have shaped their worldview (Ridley et al., 2021).

Another recommended social/political advocacy strategy is that counselors collaborate with other professionals to collect and present data on community issues to legislators and policy makers. For instance, a group of mental health providers collaborated with public health researchers and community leaders to assess mental health needs in several rural counties. Through mutual collaboration, data, and advocacy of county officials, the group was able to secure funds needed to provide telebehavioral health services to rural residents (McCord et al., 2011).

\section{Conclusion}

Advocating for racial justice and equality in today's society can place many activists at risk for burnout. Physical and mental exhaustion are burnout symptoms that may be overlooked or unaddressed by activists, making their endurance in 
racial justice movements difficult. Racial battle fatigue and a culture of selflessness can exacerbate WOC racial justice activists' ability to seek mental health resources. Counselors have the knowledge and training in empirically established counseling interventions that reduce burnout symptoms. By gaining knowledge of WOC racial justice activist experiences and mental health concerns, counselors can adapt interventions to meet activist clients' needs.

\section{Declarations}

Conflict of interest The authors declare they have no conflict of interest.

\section{References}

Abrams, J. A., Hill, A., \& Maxwell, M. (2019). Underneath the mask of the strong black woman schema: Disentangling influences of strength and self-silencing on depressive symptoms among U.S. black women. Sex Roles, 80(9/10), 517-526. https://doi.org/10.1007/s11199-018-0956-y

Ahola, K., \& Hakanen, J. (2007). Job strain, burnout, and depressive symptoms: A prospective study among dentists. Journal of Affective Disorders, 104, 103-110. https://doi.org/10.1016/j.jad.2007. 03.004

Akkus, B., Postmes, T., \& Stroebe, K. (2017). Community collectivism: A social dynamic approach to conceptualizing culture. PLoS ONE, 12(9), e0185725. https://doi.org/10.1371/journal.pone. 0185725

Allen, A. J., Davey, M. P., \& Davey, A. (2010). Being examples to the flock: The role of church leaders and African American families seeking mental health care services. Contemporary Family Therapy, 32, 117-134. https://doi.org/10.1007/s10591-009-9108-4

American Psychological Association. (2017). Multicultural guidelines: An ecological approach to context, identity, and intersectionality. Retrieved August 18, 2021 from http://www.apa.org/about/policy/multicultural-guidelines.pdf

Awa, W. L., Plaumann, M., \& Walter, U. (2010). Burnout prevention: A review of intervention programs. Patient Education and Counseling, 78, 184-190. https://doi.org/10.1016/j.pec.2009.04.008

Barker, C., Martin, B., \& Zournazi, M. (2008). Emotional self-management for activists. Reflective Practice, 9(4), 423-435. https://doi.org/10.1080/14623940802431457

Beckerman, N., \& Flaherty, H. B. (2019). Domestic violence shelters: Exploring secondary traumatic stress of female counselors. Journal of Anxiety \& Depression, 2(2), 1-11. https://doi.org/10.46527/ 2582-3264.116

Bianchi, R., Schonfeld, I. S., \& Laurent, E. (2015). Burnout-depression overlap: A review. Clinical Psychology Review, 36, 28-41. https://doi.org/10.1016/j.cpr.2015.01.004

Blaisdell, B. (2016). Schools as racial spaces: Understanding and resisting structural racism. International Journal of Qualitative Studies in Education, 29(2), 248-272. https://doi.org/10.1080/00951 8398.2015.1023228

Bradley, H., Healy, G., \& Mukherjee, N. (2005). Multiple burdens: Problems of work-life balance for ethnic minority trade union activist women. In D. M. Houston (Ed.), Work-life balance in the 21st century (1st ed., pp. 211-229). Palgrave Macmillan. https://doi.org/10.1057/9780230373594_11

Bucholtz, M. (2019). The public life of white affects. Journal of Sociolinguistics, 23(5), 485-504. https:// doi.org/10.1111/josl.12392

Cabassa, L. J., Zayas, L. H., \& Hansen, M. C. (2006). Latino adults' access to mental health care: A review of epidemiological studies. Administration and Policy in Mental Health, 33(3), 316-330. https://doi.org/10.1007/s10488-006-0040-8s

Chang, D. F., \& Berk, A. (2009). Making cross-racial therapy work: A phenomenological study of clients' experiences of cross-racial therapy. Journal of Counseling Psychology, 56(4), 521-536. https://doi.org/10.1037/a0016905 
Chang, C. W., \& Biegel, D. E. (2018). Factors affecting mental health service utilization among Latino Americans with mental health issues. Journal of Mental Health, 27(6), 552-559. https://doi.org/10. 1080/09638237.2017.1385742

Chen, C. W., \& Gorski, P. C. (2015). Burnout in social justice and human rights activists: Symptoms, causes and implications. Journal of Human Rights Practice, 7(3), 366-390. https://doi.org/10.1093/ jhuman/huv011

Cohen, R. A., Cha, A. E., Martinez, M. E., \& Terlizzi, E. P. (2020). Health insurance coverage: Early release of estimates from the national health interview survey, 2019. Retrieved August 18, 2021 from https://www.cdc.gov/nchs/data/nhis/earlyrelease/insur202009-508.pdf

Cox, L. (2009). Hearts with one purpose alone? Mapping the diverse landscapes of personal sustainability in social movements. Emotion, Space, and Society, 2, 52-61. https://doi.org/10.1016/j.emospa. 2009.05.004

Cox, L. (2011). How do we keep going? Activist burnout and sustainability in social movements. Into-ebooks.

Crenshaw, K. (1989). Demarginalizing the intersection of race and sex: Black feminist critique of antidiscrimination doctrine, feminist theory and antiracist politics. University of Chicago Legal Forum. Retrieved August 18, 2021 from http://chicagounbound.uchicago.edu/uclf/vol1989/iss 1/8

Davenport, C., Soule, S. A., \& Armstrong, D. A. (2011). Protesting while Black? The differential policing of American activism, 1960 to 1990. American Sociological Review, 76(1), 152-178. https://doi. org/10.1177/0003122410395370

Dreison, K. C., Luther, L., Bonfils, K. A., Sliter, M. T., McGrew, J. H., \& Salyers, M. P. (2018). Job burnout in mental health providers: A meta-analysis of 35 years of intervention research. Journal of Occupational Health Psychology, 23(1), 18-30. https://doi.org/10.1037/ocp0000047

Figley, C. R. (1995). Compassion fatigue: Toward a new understanding of the costs of caring. In B. H. Stamm (Ed.), Secondary traumatic stress: Self-care issues for clinicians, researchers, and educators (pp. 3-28). The Sidran Press.

Figley, C. R., \& Ludick, M. (2017). Secondary traumatization and compassion fatigue. In S. N. Gold (Ed.), APA handbooks in psychology. APA handbook of trauma psychology: Foundations in knowledge (pp. 573-593). American Psychological Association. https://doi.org/10.1037/0000019-029

Giordano, A. L., Gorritz, F. B., Kilpatrick, E. P., Scoffone, C. M., \& Lundeen, L. A. (2020). Examining secondary trauma as a result of clients' reports of discrimination. International Journal for the Advancement of Counselling. https://doi.org/10.1007/s10447-020-09411-z

González, J. A. (2015). Anti-Racist activism and community self-care at the University of Michigan. Souls, 17(1-2), 11-19. https://doi.org/10.1080/10999949.2015.998569

Gorski, P. C. (2015). Relieving burnout and the "martyr syndrome" among social justice education activists: The implications and effects of mindfulness. The Urban Review, 47, 696-716. https://doi.org/ 10.1007/s11256-015-0330-0

Gorski, P. C. (2019). Fighting racism, battling burnout: Causes of activist burnout in U.S. racial justice activists. Ethnic and Racial Studies, 42(5), 667-687. https://doi.org/10.1080/01419870.2018.14399 81

Gorski, P. C., \& Chen, C. (2015). "Frayed all over:" The causes and consequences of activist burnout among social justice education activists. Educational Studies, 51(5), 385-405. https://doi.org/10. 1080/00131946.2015.1075989

Gorksi, P. C., \& Erakat, N. (2019). Racism, whiteness, and burnout in antiracism movements: How white racial justice activists elevate burnout in racial justice activists of color in the United States. Ethnicities, 19(5), 784-808. https://doi.org/10.1177/1468796819833871

Gorski, P. C., Goodman, S., \& Rising, D. (2019). "Nobody's paying me to cry": The causes of activist burnout in United States animal rights activists. Social Movement Studies, 18(3), 364-380. https:// doi.org/10.1080/14742837.2018.1561260

Hall, C. J., Conner, K. O., \& Jones, K. (2021). The strong Black woman versus mental health utilization: A qualitative study. Health \& Social Work. https://doi.org/10.1093/hsw/hlaa036

Harrington, E. F., Crowther, J. H., \& Shipherd, J. C. (2010). Trauma, binge eating, and the "strong Black woman.” Journal of Consulting and Clinical Psychology, 78(4), 469-479. https://doi.org/10.1037/ a0019174

Jacobs, M. R., \& Taylor, T. (2011). Challenges of multiracial antiracist activism: Racial consciousness and Chief Wahoo. Critical Sociology, 38(5), 687-706. https://doi.org/10.1177/0896920511407357

Jones, P. (2007). Aftershock: Confronting trauma in a violent world: A guide for activists and their allies. Lantern Books. 
Kim, E., \& Kang, M. (2018). The effects of client-counselor racial matching on therapeutic outcome. Asia Pacific Education Review, 19, 103-110. https://doi.org/10.1007/s12564-018-9518-9

Koutsimani, P., Montgomery, A., \& Georganta, K. (2019). The relationship between burnout, depression, and anxiety: A systematic review and meta-analysis. Frontiers in Psychology. https://doi.org/ 10.3389/fpsyg.2019.00284

Laidley, T., Domingue, B., Sinsub, P., Harris, K. M., \& Conley, D. (2019). New evidence of skin color bias and health outcomes using sibling difference models: A research note. Demography, 56(2), 753-762. https://doi.org/10.1007/s13524-018-0756-6

Lenes, E., Swank, J. M., Hart, K. A., Machado, M. M., Darilus, S., Ardelt, M., Smith-Adcock, S., Rockwood Lane, M., \& Puig, A. (2020). Color-conscious multicultural mindfulness training in the counseling field. Journal of Counseling \& Development, 98, 147-158. https://doi.org/10.1002/jcad. 12309

Linder, C., \& Rodriguez, K. L. (2012). Learning from the experiences of self-identified women of color activists. Journal of College Student Development, 53(3), 383-398. https://doi.org/10.1353/csd. 2012.0048

Linehan, M. M. (2015). DBT® skills training manual (2nd ed.). Guilford Press.

Lips, H. M. (2020). Sex and gender: An introduction (7th ed.). Waveland Press.

Maslach, C., \& Gomes, M. E. (2006). Overcoming Burnout. In R. M. MacNair (Ed.), Working for peace: A handbook of practical psychology and other tools (2nd ed., pp. 43-49). Impact Publishers.

Maxwell, M., Brevard, J., Abrams, J., \& Belgrave, F. (2015). What's color got to do with it? Skin color, skin color satisfaction, racial identity, and internalized racism among African American college students. Journal of Black Psychology, 41(5), 438-461. https://doi.org/10.1177/0095798414542299

McCord, C. E., Elliott, T. R., Wendel, M. L., Brossart, D. F., Cano, M. A., Gonzalez, G. E., \& Burdine, J. N. (2011). Community capacity and teleconference counseling in rural Texas. Professional Psychology: Research and Practice, 42(6), 521-527. https://doi.org/10.1037/a0025296

McKim, L. L., \& Smith-Adcock, S. (2014). Trauma counsellors' quality of life. International Journal for the Advancement of Counselling, 36, 58-69. https://doi.org/10.1007/s10447-013-9190-Z

McRae, K., Ochsner, K. N., Mauss, I. B., Gabrieli, J., \& Gross, J. J. (2008). Gender differences in emotion regulation: An fMRI study of cognitive reappraisal. Group Processes \& Intergroup Relations, 11(2), 143-162. https://doi.org/10.1177/1368430207088035

Michaels, E. K., Reeves, A. N., Thomas, M. D., Price, M. M., Hasson, R. E., Chae, D. H., \& Allen, A. M. (2019). Everyday racial discrimination and hypertension among midlife African American women: Disentangling the role of active coping dispositions versus active coping behaviors. International Journal of Environmental Research and Public Health, 16(23), 4759-4777. https://doi.org/10.3390/ ijerph16234759

Mollen, D., \& Ridley, C. R. (2021). Rethinking multicultural counseling competence: An introduction to the major contribution. The Counseling Psychologist, 49(4), 490-503. https://doi.org/10.1177/ 0011000020986543

Moody, D. L. B., Chang, Y. F., Pantesco, E. J., Darden, T. M., Lewis, T. T., Brown, C., \& Bromberger, J. T. (2018). Everyday discrimination prospectively predicts blood pressure across 10 years in racially/ ethnically diverse midlife women: Study of women's health across the nation. Annals of Behavioral Medicine, 53(7), 608-620. https://doi.org/10.1093/abm/kay069

Moradi, B., \& Grzanka, P. R. (2017). Using intersectionality responsibly: Toward critical epistemology, structural analysis, and social justice activism. Journal of Counseling Psychology, 64(5), 500-513. https://doi.org/10.1037/cou0000203

Mughairbi, F. A., Alnajjar, A. A., \& Hamid, A. (2020). Effects of psychoeducation and stress coping techniques on posttraumatic stress disorder symptoms. Psychological Reports, 123, 710-724. https://doi.org/10.1177/0033294118825101

Neacsiu, A. D., Ward-Ciesielski, E. F., \& Linehan, M. M. (2012). Emerging approaches to counseling intervention: Dialectical behavior therapy. Counseling Psychologist, 40, 1003-1032. https://doi.org/ $10.1177 / 0011000011421023$

Nolen-Hoeksema, S. (2012). Emotion regulation and psychopathology: The role of gender. The Annual Review of Clinical Psychology, 8, 161-187. https://doi.org/10.1146/annurev-clinpsy-032511-143109

Nuñez, A., González, P., Talavera, G. A., Sanchez-Johnsen, L., Roesch, S. C., Davis, S. M., Arguelles, W., Womack, V. Y., Ostrovsky, N. W., Ojeda, L., Penedo, F. J., \& Gallo, L. C. (2016). Machismo, marianismo, and negative cognitive-emotional factors: Findings from the hispanic community health study/study of latinos sociocultural ancillary study. Journal of Latina/o Psychology, 4(4), 202-217. https://doi.org/10.1037/lat0000050 
Park, M. \& Cuevas, M. (2016). Dakota access pipeline clashes turn violent. Cable News Network. Retrieved August 18, 2021 from https://www.cnn.com/2016/11/21/us/dakota-access-pipeline-prote sts/index.html

Pigni, A. (2016). The idealist's survival kit: 75 simple ways to avoid burnout. Parralax Press.

Posluns, K., \& Gall, T. L. (2019). Dear mental health practitioners, take care of yourselves: A literature review on self-care. International Journal for the Advancement of Counselling, 42, 1-20. https:// doi.org/10.1007/s10447-019-09382-w

Richardson, A. V. (2020). Bearing witness while Black: African Americans, smartphones, and the new protest \#journalism. Oxford University Press.

Ridley, C. R., Sahu, A., Console, K., Surya, S., Tran, V., Xie, S., \& Yin, C. (2021). The process model of multicultural counseling competence. The Counseling Psychologist, 49(4), 534-567. https://doi.org/ $10.1177 / 0011000021992339$

Rodgers, K. (2010). 'Anger is why we're all here': Mobilizing and managing emotions in a professional activist organization. Social Movement Studies, 9(3), 273-291. https://doi.org/10.1080/14742837. 2010.493660

Sahu, A., Console, K., Tran, V., Xie, S., Yin, C., Meng, X., \& Ridley, C. R. (2021). A case using the process model of multicultural counseling competence. The Counseling Psychologist, 49(4), 568-585. https://doi.org/10.1177/0011000021990762

Salvagioni, D., Melanda, F. N., Mesas, A. E., González, A. D., Gabani, F. L., \& Andrade, S. M. (2017). Physical, psychological and occupational consequences of job burnout: A systematic review of prospective studies. PLoS ONE, 12(10), e0185781. https://doi.org/10.1371/journal.pone.0185781

Schaufeli, W., \& Buunk, B. (2002). Burnout: An overview of 25 years of research and theorizing. In M. Schabracq, J. Winnubst, \& C. Cooper (Eds.), The handbook of work and health psychology (pp. 383-425). Wiley. https://doi.org/10.1002/0470013400.ch19

Shah, L., Klainin-Yobas, P., Torres, S., \& Kannusamy, P. (2014). Efficacy of psychoeducation and relaxation interventions on stress-related variables in people with mental disorders: A literature review. Archives of Psychiatric Nursing, 28(2), 94-101. https://doi.org/10.1016/j.apnu.2013.11.004

Sharma, M., \& Rush, S. E. (2014). Mindfulness-based stress reduction as a stress management intervention for healthy individuals: A systematic review. Journal of Evidence-Based Complementary \& Alternative Medicine, 19(4), 271-286. https://doi.org/10.1177/2156587214543143

Sigurvinsdottir, R., \& Ullman, S. E. (2016). Sexual orientation, race, and trauma as predictors of sexual assault recovery. Journal of Family Violence, 7, 913-921. https://doi.org/10.1007/ s10896-015-9793-8

Simon-Kutscher, K., Wanke, N., Hiller, C., \& Schwabe, L. (2020). Fear without context: Acute stress modulates the balance of cue-dependent and contextual fear learning. Psychological Science, 30(8), 1123-1135. https://doi.org/10.1177/0956797619852027

Stanton, A. G., Jerald, M. C., Ward, L. M., \& Avery, L. R. (2017). Social media contributions to strong Black woman ideal endorsement and Black women's mental health. Psychology of Women Quarterly, 41(4), 465-478. https://doi.org/10.1177/0361684317732330

St. Louis Public Radio. (2017). What happened when: A day-by-day look at protests throughout the St. Louis region. St. Louis Public Radio-National Public Radio. Retrieved August 18, 2021 from https://news.stlpublicradio.org/post/what-happened-when-day-day-look-protests-throughout-stlouis-region\#stream/0

Thurston, R. C., Matthews, K. A., Chang, Y., Von Känel, R., \& Koenen, K. (2018). Association of sexual harassment and sexual assault with midlife women's mental and physical health. JAMA Internal Medicine, 179(1), 48-53. https://doi.org/10.1001/jamainternmed.2018.4886

Toporek, R. L., \& Daniels, J. (2018). American Counseling Association advocacy competencies. Retrieved August 18, 2021 from https://www.counseling.org/docs/default-source/competencies/acaadvocacy-competencies-may-2020.pdf?sfvrsn $=85$ b242c_6

Williams, D. R. (2018). Stress and the mental health of populations of color: Advancing our understanding of race-related stressors. Journal of Health and Social Behavior, 59(4), 466-485. https://doi.org/ $10.1177 / 0022146518814251$

Zhou, S., Da, S., Guo, H., \& Zhang, X. (2018). Work-family conflict and mental health among female employees: A sequential mediation model via negative affect and perceived stress. Frontiers in Psychology, 9, 544. https://doi.org/10.3389/fpsyg.2018.00544 
Publisher's Note Springer Nature remains neutral with regard to jurisdictional claims in published maps and institutional affiliations. 